\title{
Evaluation of Knowledge, Attitude and Medication Adherence among Asthmatics Outpatients in Tertiary Care Teaching Hospital-A Questionnaire Based Study
}

\author{
Chetna A. Shamkuwar ${ }^{1 *}$, Nalini Kumari², Sushant H. Meshram ${ }^{3}$, Ganesh N. Dakhale ${ }^{4}$ and Vijay M. Motghare ${ }^{5}$ \\ 'Assistant Professor, ${ }^{2}$ Post Graduate Student, ${ }^{3}$ Professor, Department of Pulmonary Medicine, B. J. Government Medical College \& Hospital, Pune, Maharashtra, India. \\ 4,5Professor, Department of Pharmacology, Government Medical College \& Hospital, Nagpur, Maharashtra, India.
}

\begin{abstract}
Background: The burden of asthma in India is estimated at more than 15 million patients. Approximately two to four percent of adult population of India is affected by asthma. In recent decade, there are striking advancement in the clinical treatment of asthma. However, in spite of this, the frequency and morbidity of asthma is increasing in several countries. The Objectives of this study was to assess the knowledge, attitude and to evaluate the medication adherence among the asthmatic patients. Methods: This is a prospective, observational, questionnaire based study conducted in a tertiary care teaching hospital of central India after the approval of institutional ethics committee for a period of six months. Face-to-face interview with the patients of specialized Asthma clinic from Pulmonary Medicine, Outpatients Department (OPD) was conducted. This was administered with questionnaires assessing the knowledge, attitude and medication adherence (Morisky 8-items medication adherence scale) towards their disease and treatment. Results: Data of 154 patients were analysed for this study. Here 80 (51.9\%) patients were male and $74(48.1 \%)$ were female. The maximum knowledge score is 16 and $66.86 \%$ of patients scored a mean score of 10.7. In attitude, the maximum score is 24 and $71.25 \%$ of patients scored a mean score of 17.1, while in adherence the maximum score is 8 and $42.50 \%$ of patients scored a mean score of 3.4. Conclusion: The present study demonstrated that the patients' specific knowledge on asthma was low. However, some patients had favourable attitude towards their disease but others did not have the necessary attitude of disease management. In addition, the medication adherence was also poor in asthmatics patients. Key words: Asthma, Knowledge, Medication adherence, Attitude.
\end{abstract}

PICTORIAL ABSTRACT

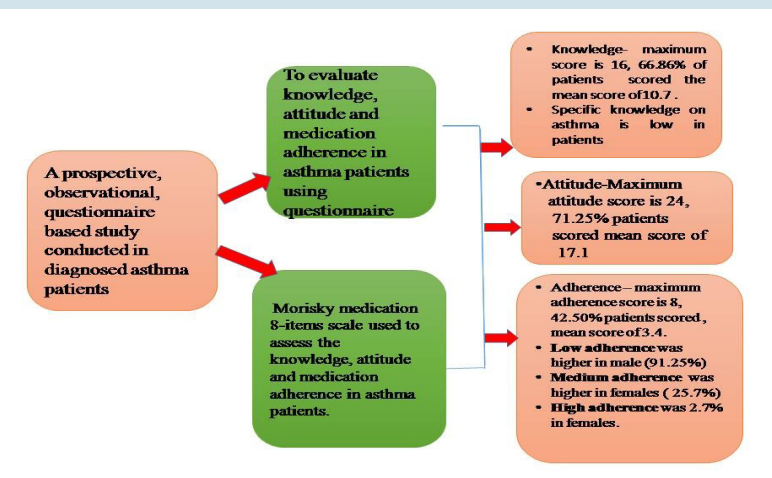

Key-message: Evaluation of knowledge, Attitude and patient medication adherence in Asthma.

Correspondence :

Dr. Chetna Ashok Shamkuwar

Department of Pharmacology, Government Medical College \& Hospital, Nagpur, Maharashtra, India.

Mobile : 91-9637615457

E-mail: chelsycosmos@rediffmail.com DOI: 10.5530/jyp.2016.1.9

\section{INTRODUCTION}

Asthma is the common and potentially serious chronic disease that imposes a substantial burden on patients, their families, and communities. ${ }^{1}$ It affects an estimated 300 million individual worldwide. Asthma is a global health problem affecting all age groups, with increasing prevalence in many developing countries. ${ }^{2} \mathrm{~A}$ recent study revealed that the national burden of asthma was estimated at 17.23 million and the prevalence ranges from $0.4 \%-4.8 \%{ }^{3}$

Patient education is one of the pillars for proper asthma management. ${ }^{4}$ The patients should have a knowledge about their asthma aetiology, pathophysiology, precipitating factors, and dangers of underuse or overuse of medications. ${ }^{5,6}$ An evaluation of patients knowledge of medicine and its use may help to screen the problems in therapy and improve the therapeutic outcomes. ${ }^{7}$

Asthma patients should be made aware about the positive attitude towards treatment, which is needed for good disease management. Asthma may be crucial if the patient is not able to judge the severity of his/her disease or symptoms or does not know the right treatment. ${ }^{8}$

The term adherence means, "sticking to a plan" for perceived benefit. This concept is applied for the patients, who have adopted and integrated a plan given by the physician. ${ }^{9}$ Non-adherence to asthma treatment leads to increased emergency care and mortality. ${ }^{10,11}$ The effect of medications depends on the efficacy and the patient adherence to the intended regimen. Adherence with medication regimens is essential for attaining maximal therapeutic benefits. ${ }^{12}$

Assessment of the knowledge, and medication adherence practice is crucial for the patients improvements and wellbeing as well as preventing them from complications. In India, there is scarcity of data regarding knowledge, attitude and medication adherence within the asthmatic patients. Hence, the present study is so designed to evaluate the knowledge, attitude and medication adherence among asthmatic patients of central India.

\section{MATERIALS AND METHODS}

This is a prospective, observational, questionnaire based study conducted at the Pulmonary Medicine, (OPD) of specialized Asthma Clinic of a tertiary care teaching hospital after the approval of institutional ethics committee. The study was conducted over a period of six - months and total 154 patients were included. The inclusion criteria of the study comprised of diagnosed asthmatic patients both male and females above 18 years of age who were on prior medication for at least two-weeks. All participants were enrolled after obtaining their informed consent. Face-to-face interviews of participants were conducted by using the assessment questionnaire for knowledge, attitude and medication 
adherence. The questionnaire was prepared in English and doctors of the Pharmacology and Pulmonary Medicine departments interviewed patients.

\section{Knowledge and Attitude Assessment}

The knowledge and attitude assessment was based on previously available questionnaire from Morisky Medication Adherence Scale (8-item questionnaires). ${ }^{13}$ It had 14 questions out of which eight were knowledge questions and six were attitude based questions.

\section{Medication Adherence Assessment}

Previously validated eight items adherence scale of Dr Morisky DE was used. ${ }^{13}$

\section{Statistical Analysis}

Descriptive statistic was presented as a mean \pm SD and percentages. The categorical variables were compared by performing Pearson's Chi-Square Test. Fisher Exact Test was used for small numbers wherever applicable. $\mathrm{P}<0.05$ was considered as statistical significance. For data analysis statistical software SATA version 13.1 is used.

\section{Table 1: Demographic details of patients $(n=154) "$}

\begin{tabular}{ccc}
\hline Variables & $\begin{array}{c}\text { Number of Patients } \\
\text { Patients }\end{array}$ & Percentages (\%) \\
\hline Gender & 80 & 51.90 \\
Female & 74 & 48.10 \\
Age in years & 18 & 11.70 \\
$15-30$ & 58 & 37.70 \\
$31-50$ & 78 & 50.64 \\
Employment status & & \\
Students & 08 & 05.19 \\
Worker & 26 & 16.90 \\
Employee & 19 & 12.30 \\
Hotal & 154 & 37.70 \\
\hline Private & 58 & 21.40 \\
& 33 & 06.50 \\
\hline
\end{tabular}

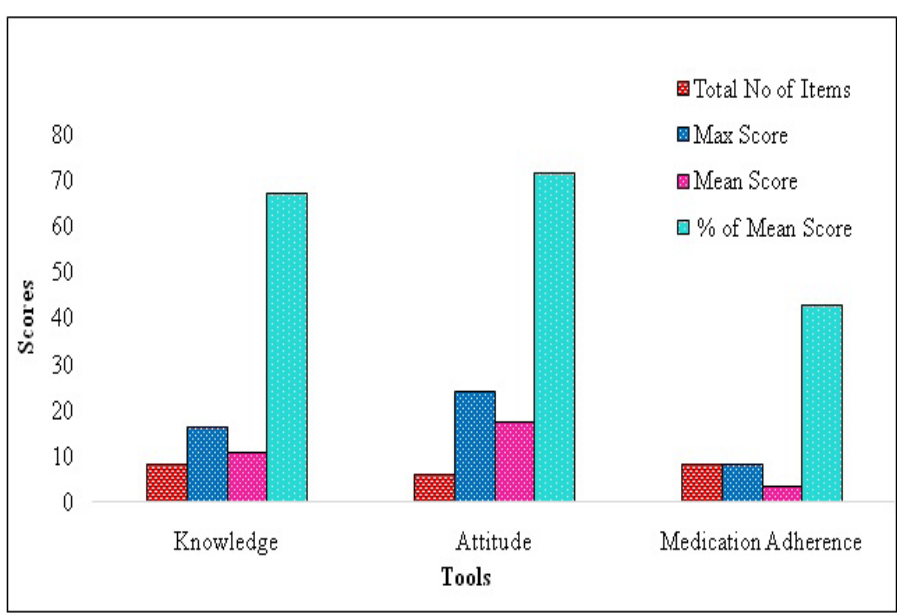

Figure 1: Assessment of the scores of knowledge, attitude and medication adherence: $(n=154)$

\section{RESULTS}

A total 154 patients were enrolled after the consideration of the inclusion criteria. Out of these, $80(51.9 \%)$ patients were male and $74(48.1 \%)$ patients were female, $78(50.6 \%)$ patients were of $\geq 50$ years of age group. The rest of the demographic details were shown in Table 1 . The scores of maximum knowledge, attitude and medication adherence are 16, 24 and 8 respectively. The percentage of mean scores of knowledge, attitude and medication adherence are $66.86 \%, 71.25 \%$ and $42.50 \%$ respectively as shown in Figure 1.

\section{Assessment of Knowledge and Attitude}

Analysis of knowledge was assessed by percentage of patients answering each item (Table 2). $99.35 \%$ of patients agreed that coughing and difficulty in breathing were the common symptoms of asthmatic patients. 98\% of patients' states that lungs and air pipes were affected during asthma. While $96.75 \%$ of patients said that medicines used for asthma helps in reducing inflammation of air pipes. Nearly, $78.58 \%$ stated that medicines used for asthma attacks constrict air pipes. 56\% of patients believed that there was no harm for asthmatic patients for being in close contact with dogs or cats. $55.84 \%$ asthma patients may have increase in symptoms or attack of asthma during hot weather. $53.24 \%$ of patients stated that some of the medicines used in asthma could be used even when they are not having the symptoms; while $51.94 \%$ of patients said that smoking could worsen asthma.

The analysis of attitude towards asthma and medication is described in Table 3.

\section{Assessment of Level of Adherence Towards Medication}

Level of adherence was significantly co-related with gender. Low adherence was significantly higher $(\mathrm{p}<0.01)$ in males $(91.25 \%)$ as compared to females (71.6\%). Medium level of adherence was significantly higher $(\mathrm{p}<0.05)$ in females $(25.5 \%)$ as compared to males $(8.75 \%)$ as shown in Figure 2.

\section{DISCUSSION}

The use of multiple medication is required at different times during the course of the disease and hence increasing patients' knowledge about their asthma therapy is vital to asthma management. ${ }^{14}$ The therapeutic achievement of medical regimen often depend on sufficient patients knowledge of basic pathophysiology of disease, symptoms of acute

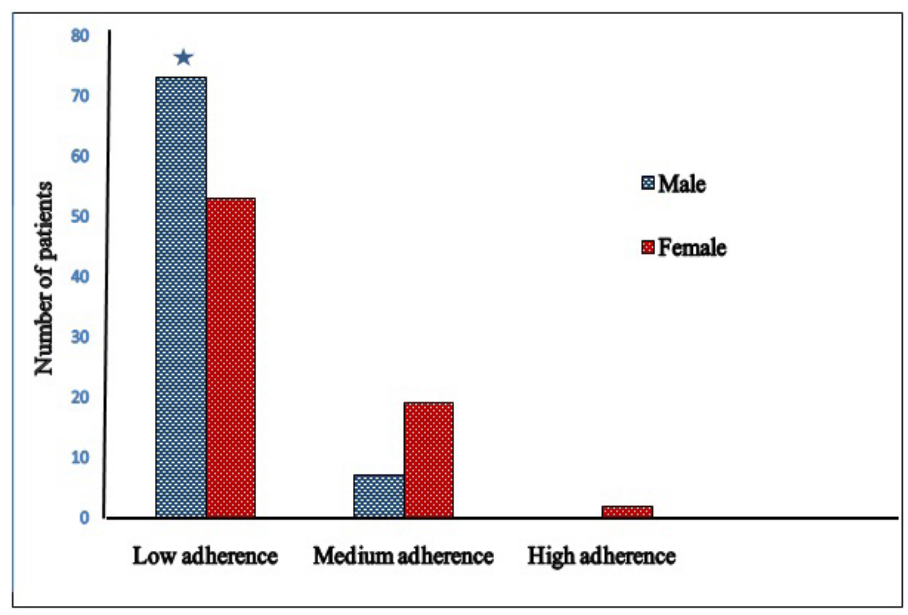

Figure 2: Assessment of level of medication adherence (MMAS-8): $(n=154)$ $* p<0.05$. Low adherence was significantly higher in males [73 (91.25\%)], with $p$ - value 0.002 . Medium level of adherence was significantly higher in females [19 (25.7\%)] with $p$-value 0.005 . 


\section{Table 2: Assessment of knowledge towards asthma and medication ( $n=154)^{\prime \prime}$}

\begin{tabular}{|c|c|c|c|c|c|}
\hline \multirow{2}{*}{ Q.No. } & \multirow{2}{*}{ Questions } & \multicolumn{4}{|c|}{ Answered } \\
\hline & & Yes & No & NA & $95 \% \mathrm{Cl}$ \\
\hline \multirow{2}{*}{1} & \multirow{2}{*}{ Lungs \& air pipes are affected when I have asthma } & 151 & 02 & 01 & \\
\hline & & {$[98.05 \%]$} & {$[01.2 \%]$} & {$[00.64 \%]$} & [ 94-99\%] \\
\hline \multirow{2}{*}{2} & \multirow{2}{*}{$\begin{array}{l}\text { There are no disadvantages for asthma patients for being in close } \\
\text { contact with dogs or cats }\end{array}$} & 21 & 86 & 47 & \\
\hline & & {$[13.64 \%]$} & {$[55.84 \%]$} & [30.5\%] & {$[08-20 \%]$} \\
\hline \multirow{2}{*}{3} & \multirow{2}{*}{$\begin{array}{c}\text { Asthma patients may have increase in symptoms or attacks of asthma } \\
\text { during hot weathers }\end{array}$} & 67 & 86 & 01 & \\
\hline & & [43.5\%] & {$[55.84 \%]$} & [0.64\%] & [35-51\%] \\
\hline \multirow{2}{*}{4} & \multirow{2}{*}{$\begin{array}{l}\text { Coughing and difficulty in breathing are the common symptom of } \\
\text { asthma patients }\end{array}$} & 153 & 01 & & \\
\hline & & [99.35\%] & {$[0.64 \%]$} & - & [96-99\%] \\
\hline \multirow{2}{*}{5} & \multirow{2}{*}{ Smoking can worsen asthma } & 80 & 10 & 64 & \\
\hline & & [51.94\%] & [06.49\%] & [41.55\%] & [43-60\%] \\
\hline \multirow{2}{*}{6} & \multirow{2}{*}{ Medicines used for asthma attacks constrict air pipes } & 121 & 32 & 01 & \\
\hline & & [78.58\%] & [20.8\%] & [00.64\%] & [71-84\%] \\
\hline \multirow{2}{*}{7} & \multirow{2}{*}{$\begin{array}{l}\text { Medicines used for asthma helps in reducing inflammation of air of } \\
\text { air pipes }\end{array}$} & 149 & 02 & 03 & \\
\hline & & [96.75] & [01.2\%] & [01.9\%] & [92-99\%] \\
\hline \multirow{2}{*}{8} & \multirow{2}{*}{$\begin{array}{l}\text { Some of the medicines used for asthma may have to be used even } \\
\text { when I am not having symptoms }\end{array}$} & 82 & 69 & 03 & \\
\hline & & [53.24\%] & [44.8\%] & [01.9\%] & {$[45-61 \%]$} \\
\hline
\end{tabular}

NA: Not answered.

Table 3: Assessment of attitude towards asthma and medication: $(n=154)$

\begin{tabular}{|c|c|c|c|c|c|c|}
\hline \multirow{2}{*}{ Q No. } & \multirow{2}{*}{ Questions } & \multicolumn{5}{|c|}{ Answered } \\
\hline & & Strongly Agree & Agree & Disagree & Strongly Disagree & $95 \% \mathrm{Cl}$ \\
\hline \multirow{2}{*}{1} & \multirow{2}{*}{$\begin{array}{l}\text { Even though I have asthma, it does not affect the pleasure } \\
\text { in my life }\end{array}$} & 14 & 75 & 05 & 62 & \\
\hline & & [09.1\%] & [48.7\%] & [03.2\%] & {$[40.25 \%]$} & {$[49.5-65.6]$} \\
\hline \multirow{2}{*}{2} & \multirow{2}{*}{$\begin{array}{l}\text { I am not worried when others come to know that I have } \\
\text { asthma }\end{array}$} & 15 & 112 & 03 & 24 & \\
\hline & & [09.7\%] & {$[72.72 \%]$} & [01.94\%] & [15.9\%] & {$[75.5-88.1]$} \\
\hline \multirow{2}{*}{3} & \multirow{2}{*}{$\begin{array}{l}\text { All the medications that I am taking for treating my asthma } \\
\text { are essential. }\end{array}$} & 25 & 126 & 02 & 01 & \\
\hline & & [06.23\%] & [81.81\%] & [00.29\%] & [00.6\%] & [94.4-99.6] \\
\hline \multirow{2}{*}{4} & \multirow{2}{*}{$\begin{array}{l}\text { I am confident that if I take my medications for asthma } \\
\text { regularly, I could live a normal life }\end{array}$} & 22 & 128 & 02 & 02 & \\
\hline & & [14.28\%] & [83.11\%] & [01.2\%] & [01.2\%] & [93.4-99.3] \\
\hline \multirow{2}{*}{5} & \multirow{2}{*}{$\begin{array}{l}\text { I am not embarrassed in taking my asthma medications in } \\
\text { public places }\end{array}$} & 22 & 112 & 03 & 17 & \\
\hline & & [14.28\%] & [72.72\%] & [01.94\%] & [11.03\%] & [80.6-91.8] \\
\hline \multirow{2}{*}{6} & \multirow{2}{*}{$\begin{array}{l}\text { I am not worried even if I have to take these medications for } \\
\text { asthma for long time }\end{array}$} & 15 & 125 & 02 & 10 & \\
\hline & & {$[9.74 \%]$} & [81.16\%] & [01.2\%] & [06.49\%] & [85.2-94.9] \\
\hline
\end{tabular}

attacks, identification of triggering factors and be able to take appropriate action to manage the symptoms. In addition, the patient's positive attitude towards illness including willingness to follow the physician's instruction plays crucial role in treatment of asthma. ${ }^{15}$

Although the onset of asthma can occur at any age but usually it is seen in children and young adults. In our study, $56.65 \%$ of patients were of advancing age ( $\geq 50$ years) which is in accordance with other study. ${ }^{3}$ The prevalence rate of asthma between males and females were similar in the present study.

Occupational asthma is induced by an agent inhaled at work place and can aggravate pre-existing asthma. The significant finding of this study is increased risk for asthma associated with occupational exposure like hotel worker, household dust, cooking fuels and fumes exposures. In our study, housewives, employees and labours (daily wages workers) were the foremost affected patients in this category. This could be the major risk factors for occupational asthma for working population. Similar finding were reported by other authors as well. ${ }^{3,16}$

If the patients are ignorant or have a partial knowledge of their disease and treatment then this can lead to poor compliance. ${ }^{17,18}$ The present study reveals that the patients' specific knowledge on asthma is low; however, the patients had positive attitude towards their disease. Our results were similar in pipeline as reported by others. ${ }^{19}$ Consequently, it is very essential to use educational tools according to low asthma knowledge. Present study also showed that $13.64 \%$ of patients did not know about the effect of staying with pets (animals) can increase the chances of asthma. Surprisingly, 30.5\% of patients did not answer this question. $78.8 \%$ of asthma patients believed that asthma medicine are going to constrict the bronchi. This clearly shows the ignorance of knowledge regarding the mechanism of action of medicine. Asthma patients of $44.8 \%$ reported that they stop their medication consumption 
when they feel better or not having symptoms of asthma. Educational methods tailored to need of each patients and effective behaviour towards disease and its management is very essential.

The maximum knowledge score is 16 , while $66.86 \%$ of patients scored a mean-score of 10.7 Similar finding was also reported in previous study. ${ }^{20}$ These scores suggested that certain knowledge was increased due to repeated contacts with health care services. However, individualised education and counselling can improve patient's knowledge.

Previous studies reported that complete trust and positive attitude is present toward the therapy for asthma. ${ }^{21,22}$ Negative attitudes can make patients more susceptible to barriers such as forgetfulness or weakness in following treatment regimens which reduces medication adherence, ${ }^{23}$ also others reported an association between patients degree of asthma control and their attitude. ${ }^{24}$ The predictor disagree (42.25\% patients) of worry to take their medication for long time, embarrassing in taking their medication in public places. Similar type of results were found in other studies. ${ }^{25}$ Patients who do not like taking medication will be more at risk of severe episodes and also important information for their management are less likely provided by doctors. It clearly shows that a better understanding of attitudes towards asthma medication should be helpful in encouraging good patient adherence to treatment. ${ }^{25}$

In attitude, maximum score is $24,71.25 \%$ of patients scored a mean-score of 17.1. Similar finding was reported in earlier study. ${ }^{20}$

Poor adherence to asthma medication treatment is a dilemma as it decreases the chance of achieving and maintaining a proper asthma control. ${ }^{26}$ A patient's motivation, beliefs and capacities in relation to medicinetaking or self-management are major influences on adherence. ${ }^{27}$

Seventy five percentage of non-compliers had a tendency to stop their treatment when they felt better; the intermittent nature of asthma is a cause of non-compliance. ${ }^{28,29}$ In our study the level of adherence to antiasthmatics were found to be low in $81.81 \%$ of patients, the statement they said that they are hassled to stick their medication regimen for longer duration of time is $15.58 \%$ and $19.48 \%$ of patients said that stopped taking their medication without telling the doctor because they felt worse when took it. Similarly, $36.36 \%$ of patient stops their medication when they feel that their health is under control.

In adherence, maximum score is 8 , and $42.50 \%$ of patients scored a mean-score of 3.4. Similar finding was also reported in previous study. ${ }^{20}$
In our study, the low level of adherence to anti-asthma medications was found to be significantly higher in males while medium level of adherence is significantly higher in females. The factors which influence on adherence to anti asthmatics is identified based on the answers given, $32.46 \%$ of patients forget to take medication along with them while on travelling, $36.36 \%$ of patients forgot to take their medication sometimes and $20.12 \%$ of people miss taking their medications for reasons other than forgetting for the past two weeks. Similar observations were reported by others. ${ }^{13,20}$

\section{CONCLUSION}

The present study established that the patients' specific knowledge on asthma is low therefore, asthma education strategies are recommended depending on the educational level of asthmatic individuals. It was also found that, most of the asthmatics patients had favourable attitude towards their disease. However, substantial numbers of people with asthma did not have the necessary attitude to contribute effectively to their disease state management. This study also demonstrated that the asthmatics patients had poor adherence to medications due to different factors may modulate adherence to asthma treatment. Therefore, the primary focus should be to identify negative factor and work towards positive changes to achieve good self-management of asthma.

\section{LIMITATION}

This study is single center study.

\section{ACKNOWLEDGEMENT}

Authors are thankful to the resident doctors of pharmacology and pulmonary medicine department of tertiary care teaching hospital for their invaluable co-operation and timely support. The authors are appreciative to Om Puran for his editorial contribution. The authors are particularly obliged to Dr. Donald E Morisky for his suggestions and providing permission to use the questionnaire.

\section{CONFLICT OF INTEREST}

Authors declared there is no conflict of interest.

\section{SUMMARY}

- The national burden of asthma was estimated at 17.23 million and the prevalence ranges from $0.4 \%-4.8 \%$.

- Using Morisky 8-item Medication Adherence Scale (MMAS-8) is to assess the knowledge, attitude and medication adherence of asthmatic patients regarding their diseases and management.

- The knowledge of asthma is low, however some of the patients had positive attitude towards their disease. The medication adherence is poor in these patients .

- The present study suggested that the strategies need to be developed through asthma education programs for patients to improve asthma management.

\section{ABBREVIATIONS USED}

OPD- Outpatients Department (OPD) ; MMAS-8: Morisky 8-item Medication Adherence Scale

\section{ABOUT AUTHORS}

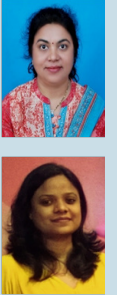

Dr. Chetna A Shamkuwar is currently positioned as Associated Professor, Department of Pharmacology, GMC, Chandrapur. She is the member secretary of Institutional Pharmacovigilance committee. Her research project, immunotherapy in tuberculosis was awarded with travel grant by international Union against Tuberculosis and Lung Disease. She has been working on survival analysis and pattern of drugs used in chronic haemodialysis patients. Her area of interest is cardiopharmacology.

Dr. Nalini Kumari: is a final year M.D. (Pharmacology) student at Govt. Medical College, Nagpur. She has conducted her dissertation on Comparative Efficacy and Safety of daily vs. alternate day dose of Rosuvastatin in Diabetic Dyslipidemia patients. Dr. Nalini has also published article in IJOP Journal on Stevens Johnson syndrome after Cranial-Thoracic Radiotherapy and Phenytoin treatment. 

Academy of Sleep Medicine, at Johns Hopkins Medical University, Baltimore, USA.2008. He is member of Research Advisory Council of India, National institute of miners health, Nagpur.

Recently he has been nominated by Ministry of Health, Govt. of India as a member of Subject Expert Committee Pulmonary medicine. He is member of Institutional Ethics Committee, B J Medical College, PUNE.

Dr. Ganesh Dakhale is currently serving as Professor in Department of Pharmacology at Govt. Medical College, Nagpur. In addition, he is also the Secretary of the Ethics Committee. Dr.Dakhale has received best teacher award for year 2011-12. Dr. Dakhale is a notable author with renowned national and international journals has published more than 40 articles. He is also reviewer of five International Journal and having interest in Research in Diabetic and Depression

Dr. Vijay M. Motghare is the Professor \& Head of Department of Pharmacology at Govt. Medical College, Nagpur. Dr. Motghare is also the Vice President of Indian Society for Rational Pharmatherapeutics (ISRPT). He is a veteran academician with more than 32 years of teaching experience. Dr. Mohtghare is also a distinguished scholarly author and has published more than 70 articles in leading national and international journals. $\mathrm{He}$ is also the contributed notable chapters to Textbook of Pharmacology ( $3^{\text {rd }}$ Edition) - by SD Seth, and published by Elsevier. He is the founder secretary of Vidharbha branch of Indian Pharmacological Society and He is also a co investigator for WHO, Reproductive Health Research Division, project on Calcium Supplementation for ' preventation of pre-eclampsia in low calcium intake women' and clinical trial of vitamin $\mathrm{C}$ and $\mathrm{E}$ supplementation in pregnancy for the preventation of pre-eclampsia'.

\section{REFERENCES}

1. Global Initiative for Asthma .Global Strategy for Asthma Management and Prevention 2014 (revision) Available from: http://www.ginasthma.org [Last accessed on 12/11/2015]

2. Global Initiative for Asthma. Pocket guide for Physician and Nurses 2014 Based on Global Strategy for Asthma Management and Prevention 2014 (revision) Available from: http://www.ginasthma.org [Last accessed on 12/11/2015]

3. Jindal SK, Aggarwal AN, Gupta D, Agarwal R, Kumar R, Kaur T, et al. Indian study on epidemiology of asthma, respiratory symptoms and chronic bronchitis in adults. Int J Tuberc Lung Dis. 2012; 16(9): 1270-7.

4. National Asthma Education and Prevention Program. Expert Panel Report 2 Guidelines for the Diagnosis and Management of Asthma.NIH publication No 97-4051.Bethesda, MD: US Dept of Health and Human Services, 1997

5. Chai SM, Tan KL, Wong JL, Eng P. Asthma knowledge among adult asthmatic outpatients in a tertiary care hospital. Asian Pac J Allergy Immunol. 2004; 22(issue ??): 81-90

6. Dorland KJ, McBurney H, Browning C. Self management beliefs: attitudes and behaviour of adults with severe life threatening asthma requiring admission to hospital. Aust Fam Physician. 2005; 34(3): 197-200.

7. Ssemaluluu R and Adome R. Patients knowledge of medication use as an equity issue in health care: Do health workers pay attention to this? EQUINET. 2006: 1-13.

8. Narhi U, Airaksinen M, Tanskanen $\mathrm{P}$, Enlund $\mathrm{H}$. The effects of a pharmacy-based intervention on the knowledge and attitudes of asthma. Patient Education and counselling. 2001; 43(2): 171-7.

9. Krass I. Impact on Medication use and Adherence of Australian Pharmacist Diabetes Care services. J Am Pharm Assoc. 2005; 45(1): 33-40.

10. Williams LK, Peterson EL, Wells K, Ahmedani BK, Rajesh Kumar R, Quantifying the proportion of severe asthma exacerbations attributable to inhaled corticosteroid non adherence. J Allergy Clin Immunol. 2011; 128(6): 1185-91.

11. Suissa S, Ernst $P$, Benayoun $S$, Baltzan M, Cai B. Low-dose inhaled corticosteroids and the prevention of death from asthma. N Engl J Med. 2000; 343(5): 332-6.

12. Rigby D. Adherence assessment tools: Drugs don't work when they're not taken. Australas J Pharm. 2007; 88(issue ??): 32-3.

13. Morisky DE, Ang A, Krousel-Wood M, Ward H. Predictive Validity of a Medication Adherence Measure for Hypertension Control. J Clin Hypertens. 2008; 10(5): 348-54.

14. Walker R, Edwards C. Clinical pharmacy and therapeutics. $2^{\text {nd }}$ edn. New York: Churchill Livingstone; 1999.
15. Wigal JK, Stout C, Brandon M. The knowledge, attitude and self efficacy Asthma Questionnaire. Chest. 1993; 104(4): 1144-8.

16. Anuradha $A$, Lakshmi Kalpana $V$, Narsingarao S. Epidemiological Study on Bronchia Asthma. Indian J Allergy Asthma Immunol. 2011; 25(2): 85-9.

17. McD Taylor D, Auble TE, Calhoun WJ, Mosesso VN. Jr Current outpatient management of asthma shows poor compliance with International consensus guidelines. Chest J. 1999; 116(6): 1638-45

18. Lindberg M, Ekstrom T, Moller M, Ahlner J. Asthma care and factors affecting medication compliance: the patients' point of view. Int $\mathrm{J}$ Qual Health Care. 2001; 13(5): 375-83

19. Sharifi L, Pourpak Z, Heidarnazhad H, Bokaie S, Moin M. Asthma knowledge attitude, and self-efficacy in Iranian asthmatic patients. Archives of Iranian Medicine. 2011; 14(5): 315-20

20. Mahendra Kumar BJ, Jose J, Kumarswamy M, Naveen MR. Assessing the knowledge, attitude and medication adherence among asthma patients in a rural population. Asian J Pharm Clin Res. 2011; 4(1): 93-7.

21. Kishan J, Singh A. Knowledge, attitude and practice (KAP) of patients and physician of Bronchial Asthma. Proceedings of XVIII National Congress on Respiratory Diseases, Jalandhar; 1998 Nov 6-7.

22. Pradel FG, Hartzema AG, Bush PJ. Asthma self-management: The perspective of children. Patient Educ Couns. 2001; 45(3): 199-209.

23. Rhee H, Belyea MJ, Ciurzynski S, Brasch J. Barriers to asthma self management in adolescents: relationships to psychosocial factors. Pediatr Pulmonol. 2009; 44(2): 183-91.

24. Jones CA, Bender BG, Haselkorn T, Fish JE, Mink DR, Peters SP, Predicting asthma control using patient attitudes toward medical care: the REACT score. Ann Allergy Asthma Immunol. 2009; 102(5): 385-92.

25. Lopez vina A. Attitudes changes needed to foster treatment adherence in patients with asthma. Arch Bronconeumol. 2005; 41(6): 334-40.

26. Smith L, Bosnic-Anticevich SZ, Mitchell B, Saini B, Krass I, Armour C. Treating asthma with a self-management model of illness behaviour in an Australian community pharmacy setting. Soc Sci Med. 2007; 64(7): 1501-11.

27. Asthma Adherence. A Guide for Health Professionals. ${ }^{\circledR}$ Copyright National Asthma Council 2005

28. Cerveri I, Locatelli F Zoia MC Corsico A Accordini, De Marco R Inter national variations in asthma treatment compliance. The results of the European Community Respiratory Health Survey (ECRHS). Eur Respir J. 1999; 14(2): 288-94.

29. Demiralay R. Comparison of the effects of three forms of individualized education on asthma knowledge in asthmatic patients. Turk J Med Sci. 2002 : 32(1): 57-64. 